\title{
DOENÇAS RESPIRATÓRIOS EM AVES ATENDIDAS NO LABORATÓRIO DE ORNITO- PATOLOGIA DA FMVZ-UNESP/BOTUCATU-SP, BRASIL, NOS ANOS DE 2005 A 2006
}

\author{
(Avian respiratory diseases attended in the Ornitopathology Laboratory of the \\ FMVZ-UNESP/Botucatu-SP, Brazil, during the years 2005 and 2006)
}

\author{
MARIETTO-GONÇALVES, G. A. ${ }^{1}$; LIMA, E. T. ${ }^{2}$; \\ ANDREATTI FILHO, R. L. ${ }^{3}$ \\ ${ }^{1} \mathrm{MV}$, Mestrando, Laboratório de Ornitopatologia da FMVZ-UNESP/Botucatu-SP; \\ gmarietto_ornito@fmvz.unesp.br* \\ ${ }^{2} \mathrm{MV}$, Doutoranda, Laboratório de Ornitopatologia da FMVZ-UNESP/Botucatu-SP; \\ et_lima@yahoo.com.br \\ ${ }^{3}$ Departamento de Clínica Veterinária da FMVZ-ŪNESP/Botucatu-SP; \\ andreatti@fmvz.com.br \\ *FMVZ-UNESP, Laboratório de Ornitopatologia, Caixa Postal: 560, \\ CEP: 18618-000, Distrito de Rubião Júnior, Botucatu-SP, Tel./Fax: (014) 3811-6293
}

\begin{abstract}
RESUMO - O trato respiratório das aves apresenta particularidades anatômicas e fisiológicas que facilitam a ocorrência de enfermidades, principalmente de origem microbiológica. O presente artigo analisa a freqüência de enfermidades respiratórias em aves domésticas e silvestres atendidas no Laboratório de Ornitopatologia do Hospital Veterinário da Faculdade de Medicina Veterinária e Zootecnia da Universidade Estadual Paulista (FMVZ-UNESP) durante os anos de 2005 e 2006. Os diagnósticos foram obtidos mediante exame clínico, radiográfico, laboratoriais (hemograma, cultivo microbiológi$\mathrm{co}$, exame parasitológico) e necropsia, sendo diagnosticado principalmente processos septicêmicos, aspergilose e micoplasmose. Das enfermidades diagnosticadas nenhuma foi de caráter zoonótico, representando pouca importância para saúde pública, porém podem acarretar em perdas de aves por parte dos proprietários como também pode haver dificuldades para tratamento e erradicação dos agentes.
\end{abstract}

Palavras-chave: Doenças respiratórias, aves, ornitopatologia, prevalência.

ABSTRACT - The respiratory tract of birds shows anatomical and physiological characteristics that facilitates the occurrence of disease, mainly those of microbiological origin. This article analyzes the frequency of respiratory diseases in domestic and wild birds treated during the years 2005-2006 at the Ornitopathology Laboratory of the Veterinary Hospital, Faculty of Veterinary Medicine and Zootecnics, São Paulo State University (FMVZ-
UNESP). Diagnoses were obtained through clinical and radiographic exams as well as haemogram, microbiological culture, parasitological tests and necropsy, being septicemic processes, aspergillosis and mycoplasmosis the most diagnosed diseases. No zoonotic threats were identified, so the entities were described as of low-impact on public health. However, the above mentioned agents can provoke death of birds and difficult for treating and eradication as well.

Key words: respiratory diseases, birds, ornitopathology.

\section{INTRODUÇÃO}

O trato respiratório das aves é composto por duas narinas, laringe, traquéia, siringe, brônquios primários, secundários e terciários, pulmões e sacos aéreos (STEINER e DAVIS, 1985).

Entre as estruturas do trato respiratório das aves, há duas que facilitam a ocorrência de enfermidades respiratórias. $O$ ducto que interliga os seios nasais a cavidade oral é extremamente estreito, disposto de tal forma que a drenagem natural de secreções é impedida (DYCE et al., 1990) e o aparelho mucociliar, que é encontrado por toda a extensão do trato respiratório (principalmente nos brônquios), não é encontrado nos sacos aéreos, o que acarreta maior gravidade no caso do comprometimento patológico destes (STEINER e DAVIS, 1985).

Os sinais clínicos das enfermidades respiratórias aviárias podem ser: diminuição de atividade, inquietação, aumento da freqüência respiratória, 
respiração profunda, sons estertores, postura de bico aberto, pescoço esticado, atos de sacudir a cabeça, lacrimejamento, espessamento de pálpebras, penas perioculares aderidas e afonia (STEINER e DAVIS, 1985; CASTRO, 2000). Alguns agentes patogênicos respiratórios concentram-se no sistema respiratório superior e podem causar inchaço e edema de parte da cabeça em virtude de infecções nos seios nasais. As lesões mais profundas observadas são traqueíte, bronquite, pneumonia e aerossaculite (CASTRO, 2000).

O presente trabalho analisa a casuística de enfermidades respiratórias em aves atendidas no Laboratório de Ornitopatologia do Hospital Veterinário da Faculdade de Medicina Veterinária e Zootecnia da Universidade Estadual Paulista, campus BotucatuSP (FMVZ-UNESP/Botucatu-SP) durante os anos de 2005 e 2006.

\section{Materiais e Métodos}

Durante o período de março de 2005 a março de 2006 foram examinadas no Laboratório de Ornitopatologia da FMVZ-UNESP/Botucatu-SP 310 aves pertencentes a 67 espécies diferentes em 14 ordens. Desse total 222 são pertencentes a avifauna brasileira e 88 são aves exóticas introduzidas no Brasil, principalmente para exploração ornamental. Os diagnósticos foram obtidos mediante exame clínico, exame radiográfico (no Centro de Diagnóstico por Imagem da FMVZ-UNESP/Botucatu-SP), exames laboratoriais (exames hematológicos foram realizados no Laboratório Clínico Veterinário da FMVZ-UNESP/ Botucatu-SP) e necropsia.

Mediante a queixa do proprietário realizava-se a inspeção física para observação da presença de secreções oculares, nasais ou orais e com o auxílio de um estetoscópio analisava-se a presença de sons estertores respiratórios. Após a constatação de tais sinais clínicos as aves eram submetidas a exames radiográficos para observação de alterações visíveis por este exame.

Coletava-se em seguida sangue, onde a quantidade variou conforme o porte da ave e a veia puncionada (além do porte) variou conforme o estado de hidratação apresentado no momento da coleta (variando entre veia metatarsal, tibial, ulnar, jugular e/ou punção intracardíaca), para a realização de exames hematológicos (hematimetria, leucometria e contagem de trombócitos), conforme PIERSON (2000), e sorológicos (soroaglutinação rápida para Mycoplasma gallisepticum - Myco-Galli Teste ${ }^{\circledR}$ M. synoviae - Synovtest ${ }^{\circledR}$, ambos do Laboratório Biovet).

Exames microbiológicos foram realizados através de cultivo de secreções, swab traqueal e cultivo de órgãos (em caso de óbitos). Para análise bacteriana as amostras eram primeiramente cultivadas em Caldo Cérebro-Coração e Selenito-Cistina por 24 horas a $37^{\circ} \mathrm{C}$ e semeadas em Ágar MacConkey, Ágar Dextrose Batata e Ágar Sangue e caracterizados através da analíse bioquímica e/ou coloração de Gram, conforme HOLí et al. (1990) e CRITTER et al. (2007). Para análise fúngica as amostras de secreções eram enriquecidas em Água peptonada Tamponada e semeadas em Ágar Sabouraud Dextrosado, já amostras de órgãos eram depositadas diretamente no Ágar Sabouraud Dextrosado, cultivadas por cinco dias a $37^{\circ} \mathrm{C}$ e caracterizados com a coloração de Azul de lactofenol, conforme ANDREATTI FILHO (2007) e CRITTER et al. (2006).

Em casos de óbito, coletaram-se também amostras de tecidos, com presença de lesões macroscópicas, sempre incluindo no mesmo fragmento áreas de tecido alterado e não alterado, que foram fixadas em solução de formalina $10 \%$, incluído em parafina e corados em Eosina-Hematoxilina ou Ácido Periódico de Schiff, conforme SEQUEIRA (2007).

\section{Resultados}

Dos 310 casos atendidos, $38(12,2 \%)$ apresentaram distúrbios respiratórios, em 21 espécies diferentes de aves, onde o Galo doméstico (Gallus gallus domesticus) foi a espécie mais acometida por enfermidades respiratórias (TABELA 1), sendo diagnosticado quadros septicêmicos com comprometimento respiratório, aspergilose, micoplasmose, cólera aviária, singamose e alergia respiratória. Destes, se destacaram principalmente os quadros septicêmicos, com $29 \%$ dos casos, aspergilose e micoplasmose, ambos com 26\% (GRÁFICO 1). 
TABELA 1 - RELAÇÃO DOENÇA/ESPÉCIE OBSERVADA NO LABORATÓRIO DE ORNITOPATOLOGIA DO AFETADA DURANTE O PERÍODO ESTUDADO; N: NÚMERO DE AVES AFETADAS

Septicemia com comprometimento respiratório

Agapornis personata

Amazona aestiva

Ardea cocoi

Bubulcus ibis

Cairina moschata

Gallus gallus domesticus

Nimphycus hollandicus

Rhamphostos toco

Rhea americana

Serinus canarius

\section{Aspergilose}

Aix spansa

Columba livia

Gallus gallus domesticus

Lonchura striata

Oryzoborus angolensis

Streptotelia risoria

Taeniopygia guttata

\section{Micoplasmose}

Anas platyrinchus

Cairina moschata

Columba livia

Gallus gallus domesticus

Neophema elegans

Nimphycus hollandicus

Sicalis flaveola

Struthio camelus

\section{Cólera aviária}

Gallus gallus domesticus

Pavo cristatus

Serinus canarius

\section{Singamose}

Gallus gallus domésticus
Agaporne Mascarado 1

Papagaio verdadeiro 1

Maguari 1

Garça vaqueira 1

Pato do mato 1

Galo doméstico 2

Calopsita 1

Tucano toco 1

Ema 1

Canário 1

Marreca carolina 1

Pombo doméstico 1

Galo doméstico 1

Manon 2

Curió 1

Pombo de colar 1

Mandarim 3

Marreco de Pequim 1

Pato do mato 1

Pombo doméstico 1

Galo doméstico 2

Periquito elegante 1

Calopsita 1

Canário da terra 2

Avestruz 1

Galo doméstico

Pavão real 1

Canário 3

Galo doméstico 1

Papagaio verdadeiro 1 


\section{GRÁFICO1-ÍNDICEDEFREQÜÊNCIADOSDISTÚRBIOSDIAGNOSTICADOSEMTRATORESPIRATÓRIODEANI- MAIS, OBSERVADOSNOLABORATÓRIODEORNITOPATOLOGIADAFMVZ-UNESP(BOTUCATU-SP) DURANTE O PERÍODO ANALISADO. (2005-2006). ( $\mathrm{N}=38)$}

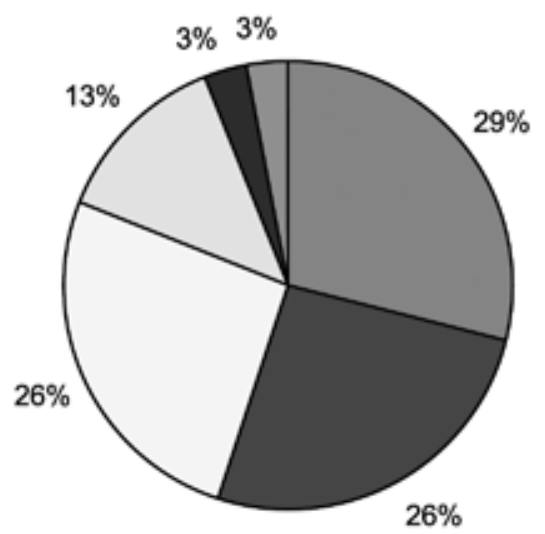

\section{Discussão}

Durante o período estudado os distúrbios respiratórios foram o segundo problema mais comum no Laboratório de Ornitopatologia da FMVZ-UNESP/ Botucatu-SP, perdendo apenas para distúrbios digestivos. Das seis enfermidades respiratórias diagnosticadas nenhuma foi considerada como potencialmente zoonótica, representando pouca importância para a saúde pública, porém podendo acarretar perdas de aves dos proprietários como também podendo haver dificuldades para o tratamento e erradicação dos agentes.

Dos quadros septicêmicos observados, em $80 \%$ isolou-se Escherichia coli e em $20 \%$ isolou-se Staphylococcus spp. hemolíticos. Em aves, a infecção por E. coli (colissepticemia) é considerada secundária a outros agentes e a manifestação da doença é extra-intestinal onde em aves adultas a via respiratória é de máxima importância como via de infecção (FERREIRA e KNÖBL, 2000; ANDREATTI FILHO, 2007a). Amostras patogênicas de E. coli, muitas vezes auxiliadas por condições ambientais ou outros agentes infecciosos, atuando como fatores predisponentes, acabam determinando a invasão do sistema respiratório pela bactéria (ANDREATTI FILHO, 2007a). A colissepticemia é uma doença importante para aves industriais como também para aves de companhia (GERLACH, 1986a; BARNES e GROSS, 1997). Os Staphylococcus spp. são bactérias que fazem parte da microbiota da pele e mucosas, em especial no trato respiratório e digestório, sendo freqüentemente relacionados a infecções em aves. Apesar do conceito de que a maioria das espécies de Staphylococcus serem consideradas como flora

$\square$ Septicemia
$\square$ Aspergilose
$\square$ Micoplasmose
$\square$ Cólera aviária
$\square$ Singamose
$\square$ Alergia

normal, algumas cepas, principalmentes de $S$. aureus, são altamente patogênicas causando doenças graves, mas em geral as infecções (estafilococose) são secundárias a outras doenças (FERREIRA e FERREIRA, 2000; LANGONI, 2007), sendo que a capacidade de hemólise é característica de cepas patogênicas (GERLACH, 1986a).

A aspergilose é uma doença causada por fungos do gênero Aspergillus, de ocorrência mundial, onde são descritas a ocorrência em 19 das 27 ordens aviárias. As espécies mais freqüentemente isoladas são o $A$. flavus e $A$. fumigatus, onde esta ultima é a mais isolada (KEYMER, 1982; ANDREATTI FILHO, 2007b). É uma doença secundária multifatorial onde se destacam como fatores primários principalmente a imunossupressão, stress, má nutrição, corticoideterapia ou antibioticoterapia prolongada (CAMPBELL, 1986). Ao contrário do encontrado na literatura, nos casos observados isolou-se mais $A$. flavus $(60 \%$ dos casos) do que $A$. fumigatus.

A micoplasmose é causada por bactérias do gênero Mycoplasma, onde se destacam como principais causadoras de doenças em aves as espécies M. gallisepticum (em aves domésticas e selvagens), M. synoviae (em galinhas), M. iowae e M. meleagridis (ambas em perus) e apresentam ocorrência mundial (NASCIMENTO, 2000; METTIFOGO e FERREIRA, 2007). São bactérias intracelulares que colonizam a mucosa do trato respiratório e urogenital do hospedeiro que em algumas vezes não apresentam lesões, ou seja, com manifestação clínica inaparente (T-W-FIENNES, 1982; GERLACH, 1986b). Dos casos diagnosticados, $90 \%$ foram micoplasmoses causados por M. gallisepticum e 10\% por M. Synoviae, sendo observado um caso de Doença Respiratória 
Crônica Complicada (sendo isolado E. coli) em Avestruz (Struthio camelus). Para o diagnóstico de micoplasmose, só a utilização de soroaglutinação rápida (SAR) em placa não é suficiente apesar de ser um exame sensível, mas levou-se em consideração a positividade do SAR em conjunto com a sintomatologia clínica apresentada e a resposta terapêutica positiva, tendo-se tratado todos os casos com Tetraciclina, sendo a dosagem variada de acordo com peso e a espécie aviária, conforme CARPENTER (2005).

A cólera aviária é uma doença contagiosa, causada pela bactéria Pasteurella multocida, que acomete aves domésticas e silvestres de diferentes ordens, com ocorrência esporádica e enzooticamente em todo mundo, sendo comum em regiões com estações frias (GAMA e NASCIMENTO, 2000; LIMA e ANDREATTI FILHO, 2007). Apresenta uma evolução clínica rápida e com alta mortalidade de aves na forma aguda, mas existe variância de virulência entre cepas onde inclusive a $P$. multocida pode ser isolada de aves sadias (GERLACH, 1886b; GAMA e NASCIMENTO, 2000). Apesar de ser facilmente encontrado no trato respiratório e ser uma doença altamente contagiosa, atribui-se a baixa incidência da cólera aviária (13\%) no período avaliado devido à correlação com sazonalidade.

A singamose é causada pelo helminto hematófago Syngamus trachea, um nematóide de transmissão direta ou indireta (através de anelídeos, artrópodes e moluscos) que parasita a traquéia e brônquios de aves de diversas ordens, causando irritação na mucosa com muita produção de muco e acomete principalmente aves jovens (URQUHART et al., 1990; VASCONCELOS, 2000), sendo muito comum em criações com piso de terra (URQUHART et al., 1990).

Processos alérgicos respiratórios podem ser causados por inalação de gases irritantes (como amônia, derivados de petróleo, fumaça de cigarro, perfumes, produtos de limpeza voláteis e outros), que causam hipersensibilidade na mucosa respiratória e choques anafiláticos. A etiologia, na maioria das vezes, pode não ser clara sendo o diagnóstico obtido mediante ação terapêutica com anti-histamícos, sendo que o auxílio do exame de hemograma pode ajudar no caso de suspeita, onde se observa uma grande quantidade de eosinófilos (ARNALL e PETRAK, 1982; STEINER e DAVIS, 1985; LOTHTOP et al., 1986).

\section{CONCLUSÃO}

As principais enfermidades respiratórias observada durante o período de 2005 a 2007 foram causadas por processos septicêmicos, seguido por aspergilose e micoplasmose, processos esses que são facilitados pela conformação anatômica e fisiologia das aves, associado ao mau manejo por parte dos proprietários.

\section{REFERÊNCIAS}

ANDREATTI FILHO, R.L. Saúde Aviária e Doenças. São Paulo: Roca, p. 18-29. 2007.

ANDREATTI FILHO, R.L. Colibacilose Aviária. In: ANDREATTI FILHO, R.L. Saúde Aviária e Doenças. São Paulo: Roca, p. 112-117. 2007 a.

ANDREATTI FILHO, R.L. Doenças fúngicas. In: ANDREATTI FILHO, R.L. Saúde Aviária e Doenças. São Paulo: Roca, p. 236-245. 2007b.

ARNALL, L.; PETRAK, M.L. Diseases of the Respiratory System. In: PETRAK, M.L.. Diseases of Cage and Aviary Birds. 2. ed. Philadelphia: Lea \& Fabiger, p. 395-421. 1982

BARNES, H.J.; GROSS, W.B. Collibacillosis. In: CALNEK, B.W.; BARNES, H.J.; BEARD, C.W.; MCDOUGALD, L.R.; SAIF, Y.M. Diseases of Poutry. 10. ed. lowa, The lowa State University Press, $p$ 131-141. 1997

CAMPBELL, T.W. Mycotic Diseases. In: HARRINSON, G.J.; HARRINSON, L.R. Clinical Avian Medicine and Surgery. Philadelphia: W.B. Saunders Company, p. $464-471.1986$

CARPENTER, J.W. Exotic Animal Formulary. 3. ed. Missouri: Elsevier Saunders, p. 564. 2005

CASTRO A.G.M. Enfermidades do Sistema Respiratório. In: BERCHIERI JÚNIOR, A.; MACARI, M. Doenças das Aves. Campinas: FACTA, p. $71-74.2000$ 
CRITTER, R.B.O.; KUIBIDA, K.V.; UHEARA, T.I.; PARRA, P.N.S.; CARVALHO, A.T. Métodos de Diagnósticos - Microbiológicos, Sorológicos e Anatomopatológicos. In: ANDREATTI FILHO, R.L. Saúde Aviária e Doenças. São Paulo: Roca, p. $9-17.2007$

DYCE, K.M.; SACK, W.O.; WENSING, C.J.G. Tratado de Anatomia Veterinária. Guanabara Koogan: Rio de Janeiro, p. 567. 1990

FERREIRA, A.J.P.; FERREIRA, C.S.A.F. Estafilococose e Estreptococose Aviária. In: BERCHIERI JÚNIOR, A.; MACARI M. Doenças das Aves. Campinas: FACTA, p. 209-215. 2000

FERREIRA, A.J.P.; KNÖBL, T. Colibacilose Aviária In: BERCHIERI JÚNIOR, A.; MACARI, M. Doenças das Aves. Campinas: FACTA, p. 197-207. 2000

GAMA, N.M.S.Q.; NASCIMENTO, V.P. Coriza infecciosa das Galinhas e Pasteureloses. In: BERCHIERI JÚNIOR; A.; MACARI, M. Doenças das Aves. Campinas: FACTA, p. 225-237. 2000

GERLACH, H. Bacterial diseases. In: HARRINSON, G.J.; HARRINSON, L.R. Clinical Avian Medicine and Surgery. Philadelphia: W.B. Saunders Company, p. 434-453. 1986ba

GERLACH, H. Mollicutes (Mycoplasma, Acholeplasma, Ureaplasma In: HARRINSON, G.J.; HARRINSON, L.R. Clinical Avian Medicine and Surgery. Philadelphia: W.B. Saunders Company, p. 454-456. 1986b

HOLT, J.G.; KRIEG, N.R.; SNEATH, P.H.A.; STALEY, J.T.; WILLIAMS, S.T. Bergey's Manual of Determinative Bacteriology. 9. ed. Baltimore: Willians \& Wilkins, p. 787. 1990.

KEYMER, I.F. Mycoses. In: PETRAK, M.L. Diseases of Cage and Aviary Birds. 2. ed. Philadelphia: Lea \& Fabiger, p. 599-605. 1982

LANGONI, H. Estafilococose aviária. In: ANDREATTI FILHO, R.L. Saúde Aviária e Doenças. São Paulo: Roca, 2007. p. 127-132.
LIMA E.T.; ANDREATTI FILHO, R.L. Pasteureloses Aviária. In: ANDREATTI FILHO, R.L. Saúde Aviária e Doenças. São Paulo: Roca, p. 122-126. 2007

LOTHTOP, C.; HARRINSON, G.J.; SCHULTZ, D.; UTTERIDGE. Miscellaneous Diseases. In: HARRINSON G.J., HARRINSON L.R. Clinical Avian Medicine and Surgery. Philadelphia: W.B. Saunders Company, p. 525-536. 1986

METTIFOGO, E.; FERREIRA, A.J.P. Micoplasmose Aviária. In: ANDREATTI FILHO, R.L. Saúde Aviária e Doenças. São Paulo: Roca, p. 147-151. 2007

NASCIMENTO, E.R. Micoplasmoses. In: BERCHIERI JÚNIOR, A.; MACARI, M. Doenças das Aves. Campinas: FACTA, p. 219-224. 2000

PIERSON, F.W. Laboratory Techniques for Avian Hematology. In: FELDMAN, B.F.; ZINKL, J.G.; JAIN, N.C. Schalm's Veterinary Hematology. 5. ed. Baltimore: Lippincott Willians \& Wilkins, p. 11451146. 2000

SEQUEIRA, J.L. Diagnóstico Histopatológico. In: ANDREATTI FILHO, R.L. Saúde Aviária e Doenças. São Paulo: Roca, p. 18-29. 2007

STEINER C.V.; DAVIS R.B. Patologia de las Aves Enjauladas. Zaragoza: Editorial Acribia, p. 165. 1985.

T-W-FIENNES, R.N. Diseases of Bacterial Origin. In: PETRAK M.L. Diseases of Cage and Aviary Birds. 2. ed. Philadelphia: Lea \& Fabiger, p. 497515. 1982.

URQUHART, G.M.; ARMOUR, J.; DUNCAN, J.L.; DUNN, A.M.; JENNINGS, F.W. Parasitologia Veterinária. Rio de Janeiro: Guanabara Koogan, p. 306.1990

VASCONCELOS, O.T. Parasitoses em Aves de Produção Industrial. In: BERCHIERI JÚNIOR, A.; MACARI, M. Doenças das Aves. Campinas: FACTA, p. $423-428.2000$

Recebido para publicação:

$22 / 06 / 2007$ Aprovado: $25 / 03 / 2008$ 